\title{
Papillary Adenocarcinoma
}

National Cancer Institute

\section{Source}

National Cancer Institute. Papillary Adenocarcinoma. NCI Thesaurus. Code C2853.

A morphologic variant of adenocarcinoma. It is characterized by the presence of a papillary growth pattern. Representative examples include thyroid gland papillary carcinoma, invasive papillary breast carcinoma, and ovarian serous surface papillary adenocarcinoma. 